\title{
Optimization of a New Extraction Technique for Analysis of Verbenone and cis-Verbenol in Pine Seeds
}

\author{
Ali Liazid', Gerardo F. Barbero ${ }^{2}$, Miguel Palma ${ }^{2, 凶}$, Jamal Brigui ${ }^{1}$, Carmelo G. Barroso ${ }^{2}$ \\ ${ }^{1}$ Département de Genie Chimique, Faculté des Sciences et Techniques de Tanger, Université Abdelmalek Essaadi, Tanger, Morocco \\ ${ }^{2}$ Grupo de Investigación Químico Analítico del Vino y Productos Agroalimentarios, Departamento de Química Analítica, Facultad de Ciencias, \\ Universidad de Cádiz, Apdo 40, Cádiz, Puerto Real 11510, Spain; E-Mail: miguel.palma@uca.es
}

Received: 4 March 2007 / Revised: 19 June 2007 / Accepted: 25 June 2007

Online publication: 1 September 2007

\begin{abstract}
Results from a systematic study of the factors affecting extraction of cis-verbenol and verbenone from pine seeds are presented. Five extraction conditions were investigated: extraction solvent, method of extraction, extraction temperature, volume of solvent, and the ratio of the mass of sample to the amount of extraction solvent. The resulting optimized method uses magneticstirring-assisted extraction of pine seeds $(5 \mathrm{~g})$ with ethyl acetate $(75 \mathrm{~mL})$ for $20 \mathrm{~min}$, at room temperature. RSDs were less than 5\% for both compounds. GC-FID was used for quantification of cis-verbenol and verbenone in the extracts.
\end{abstract}

\section{Keywords}

Gas chromatography

Extraction

Pine seeds

Pinus pinaster

cis-Verbenol

Verbenone

\section{Introduction}

There have been many studies of the bioactivity of volatile components, especially monoterpenes, in the essential oil from pines. The antibacterial, antimicrobial, and antifungal activity of natural extracts containing monoterpenes are well known [1-4]. Among the monoterpenes identified in the extracts, two compounds, cis-verbenol $\left(\mathrm{C}_{10} \mathrm{H}_{16} \mathrm{O}\right)$ and verbenone $\left(\mathrm{C}_{10} \mathrm{H}_{14} \mathrm{O}\right)$, have been shown to be highly bioactive [5]. Verbenone has a repellent effect on the beetles that attack pine trees; the consequent effect is to reduce the number of beetles to below a level that would overcome the natural resistance of attacked trees [6]. Another effect is inhibition of feeding of the pine weevil, both male and female [7]. A strong stimulant effect, on females only, of the old house borer has also been shown [8]. cis-Verbenol is also used to control harmful insects and is an intermediate in the synthesis of valuable perfume and medicinal substances $[9,10]$.
Techniques for extraction of simple monoterpenes from solid material have usually been based on distillationextraction and hydrodistillation [11-14] using a variety of solvents. These techniques often require long extraction times (between 1 and $3 \mathrm{~h}$ ), however. Several more rapid extraction techniques have been used in recent years, for example supercritical-fluid extraction using carbon dioxide [15], distillation under reduced pressure, simultaneous purging and solvent extraction [16], solid-phase trapping solvent extraction, headspace solid-phase microextraction, reduced-pressure steam distillation, and simultaneous steam distillation-solvent extraction [17]. In the work discussed in this paper extraction of verbenone and cis-verbenol from $P$. pinaster seeds using both ultrasound-assisted extraction (UAE) and magnetic-stirringassisted extraction (MSAE) has been evaluated.

Improvement of extraction efficiency by use of ultrasound is attributed to the phenomenon of cavitation of the solvent caused by passage of the ultrasonic wave. Cavitation bubbles are produced and compressed during application of the ultrasound. The increase in pressure and temperature caused by the compression leads to the collapse of the bubble. With collapse of bubble a shock wave passes through the solvent, enhancing mixing [18]. Ultrasound also has a mechanical effect, enabling greater penetration of solvent into the sample matrix, increasing 
Table 1. Conditions used in the experimental design

\begin{tabular}{|c|c|c|c|c|c|c|c|}
\hline Expt. & Solvent & Method $^{\mathrm{a}}$ & $\begin{array}{l}\text { Temp. } \\
\left({ }^{\circ} \mathrm{C}\right)\end{array}$ & $\begin{array}{l}\text { Vol. } \\
(\mathrm{mL})\end{array}$ & $\begin{array}{l}\text { Mass } \\
(\mathrm{g})\end{array}$ & $\begin{array}{l}\text { Verbenone } \\
(\%)^{\mathrm{b}}\end{array}$ & $\begin{array}{l}\text { cis-Verbenol } \\
(\%)^{\mathrm{b}}\end{array}$ \\
\hline 1 & $\mathrm{DCM}$ & US & 10 & 25 & 10 & $27.4 \pm 0.8$ & $25.9 \pm 0.5$ \\
\hline 2 & AcOEt & US & 10 & 25 & 5 & $31.7 \pm 1.0$ & $30.6 \pm 0.5$ \\
\hline 3 & DCM & MS & 10 & 25 & 5 & $44.7 \pm 1.4$ & $40.0 \pm 0.4$ \\
\hline 4 & AcOEt & MS & 10 & 25 & 10 & $25.9 \pm 1.2$ & $24.6 \pm 0.5$ \\
\hline 5 & DCM & US & 50 & 25 & 5 & $36.5 \pm 1.1$ & $36.7 \pm 0.5$ \\
\hline 6 & AcOEt & US & 50 & 25 & 10 & $29.5 \pm 0.9$ & $27.8 \pm 0.7$ \\
\hline 7 & DCM & MS & 50 & 25 & 10 & $22.3 \pm 0.4$ & $19.8 \pm 0.5$ \\
\hline 8 & AcOEt & MS & 50 & 25 & 5 & $46.2 \pm 1.4$ & $44.7 \pm 0.9$ \\
\hline 9 & DCM & US & 10 & 50 & 5 & $73.7 \pm 2.8$ & $67.8 \pm 1.3$ \\
\hline 10 & AcOEt & US & 10 & 50 & 10 & $42.3 \pm 1.9$ & $40.2 \pm 1.0$ \\
\hline 11 & $\mathrm{DCM}$ & MS & 10 & 50 & 10 & $48.6 \pm 1.9$ & $45.3 \pm 1.0$ \\
\hline 12 & AcOEt & MS & 10 & 50 & 5 & $94.7 \pm 3.0$ & $92.6 \pm 1.8$ \\
\hline 13 & $\mathrm{DCM}$ & US & 50 & 50 & 10 & $56.0 \pm 1.6$ & $51.2 \pm 1.0$ \\
\hline 14 & AcOEt & US & 50 & 50 & 5 & $97.3 \pm 3.1$ & $93.0 \pm 1.9$ \\
\hline 15 & DCM & MS & 50 & 50 & 5 & $100.0 \pm 3.0$ & $100.0 \pm 2.0$ \\
\hline 16 & AcOEt & MS & 50 & 50 & 10 & $48.2 \pm 1.5$ & $45.4 \pm 1.5$ \\
\hline
\end{tabular}

${ }^{\text {a }}$ US ultrasound-assisted, MS magnetic-stirring-assisted

${ }^{b}$ Relative to the amount obtained in the extraction with the highest recovery (no. 15)

the contact surface area between the solid and liquid phases. This effect, coupled with enhanced mass transfer and substantial disruption of cells, via cavitation bubble collapse, increases the release of intracellular products into the bulk medium. Use of high temperatures in UAE can increase the efficiency of the extraction process by increasing the number of cavitation bubbles formed [18-20]. The high energy involved and the high temperature reached can cause the most volatile compounds to evaporate, however, reducing the efficiency of the extraction.

MSAE is usually found to be a less efficient method of extraction than UAE, because the energy introduced to the system does not overcome the interactions between the compounds to be extracted and the matrix. Because it is a more gentle method of extraction, however, it could be more suitable for volatile compounds.

Although both MSAE and UAE have been applied to the analysis of several terpenes, the literature contains no references to their use in the analysis of cisverbenol and verbenone.

\section{Experimental}

\section{Sample}

Seeds from $P$. pinaster were obtained from the Station Regionale des Semences de Chefchaouan (Chefchaouan, Morocco). They were collected in the Rif Occidental of Morocco.

\section{Chemicals and Solvents}

(1S)-(-)-Verbenone and (S)-cis-verbenol, were obtained from Sigma-Aldrich Chemie (Schnelldorf, Germany). Their purities were 94 and $99 \%$, respectively.

All reagents used were of analytical grade. Ethyl acetate and dichloromethane were purchased from Scharlab (Barcelona, Spain) and octan-2-ol from Merck (Darmstadt, Germany).

\section{Chromatographic Analysis}

All extracts were analyzed by use of a Hewlett-Packard (Palo Alto, CA, USA) 5,890 Series II gas chromatograph equipped with flame ionization detection (FID) and split-splitless injection. Compounds were separated on a $60 \mathrm{~m} \times 0.32 \mathrm{~mm}$ fused-silica capillary column coated with a $0.25-\mu \mathrm{m}$ film of DB-Wax (J\&W Scientific, Folsom, CA, USA).

The verbenone and cis-verbenol peaks obtained from extracts of $P$. pinaster seeds were identified by comparison of their retention times with those of standards, and by GC-MS, performed with a GC 8000 coupled to a MD 800 mass detector (Fisons Instruments, Milan, Italy). Electron-impact mass spectra were acquired at electron energy of $70 \mathrm{eV}$ in the range 40-400 a.m.u. Mass spectra were compared with those in a commercial database of mass spectra (Wiley, Chichester, UK).

For both GC and GC-MS splitless injection was performed with the injector purge closed for $2 \mathrm{~min}$. The injector temperature was $200{ }^{\circ} \mathrm{C}$ and the oven temperature was maintained at $40{ }^{\circ} \mathrm{C}$ for $5 \mathrm{~min}$ and then programmed at $2{ }^{\circ} \mathrm{C}$ $\min ^{-1}$ to $230^{\circ} \mathrm{C}$, which was maintained for $20 \mathrm{~min}$ (isothermal). Helium was used as carrier gas at $40 \mathrm{kPa}$.

Compounds were quantified by $\mathrm{GC}$ FID. During optimization of the method of extraction recovery was calculated relative to the extraction from which the largest amounts of verbenone and cisverbenol were obtained (largest chromatographic peak area relative to that of the internal standard).

The compounds were extracted by using an ultrasonic water bath of power 400 W (J.P. Selecta, Barcelona, Spain) for UAE. The working frequency was $40 \mathrm{kHz}$. A magnetic stirring plate (model 1002, Jenway, UK) working at $500 \mathrm{rpm}$ was used for MSAE.

Seeds from $P$. pinaster were ground in a coffee grinder, freeze-dried, and stored at $-20{ }^{\circ} \mathrm{C}$ until extraction, to guarantee a homogenous sample for all the experiments and that no changes occurred during development of the method of extraction.

Extraction by both UAE and MSAE was performed with dichloromethane (DCM) and ethyl acetate (EtOAc) using high and low temperatures, volumes, and masses. All extractions were performed in triplicate. Sample (5 or $10 \mathrm{~g}$ ) was placed in a glass beaker with 25 or $50 \mathrm{~mL}$ DCM or EtOAc and extracted for $20 \mathrm{~min}$. Internal standard (octan-2-ol, 100 ppm) was then added and the solution was filtered through a $0.45-\mu \mathrm{m}$ Nylon syringe filter (Millex-HN, Millipore, Ireland).

An experimental design was used for method development. Table 1 shows the experimental conditions evaluated in the experimental design. Minitab software (State College, PA, USA) was used for the experimental design and for treatment of the resulting information.

\section{Results and Discussion}

A fractional factorial experimental design was used to optimize the extraction variables organic solvent, extraction method, extraction temperature, volume of solvent, and mass of sample. The starting values for these variables were based on results from previous work with terpenes [21, 22]. A fractional experimental design was used to reduce the 
number of experiments. Thirty-two experiments would normally be needed to evaluate the effects of five variables at two levels; a fractional design enables use of 16 experiments instead of 32. Statistical and graphical treatment of the results affords sufficient information to ascertain the best extraction conditions. This type of experimental design has produced good results in previous work with both real and spiked samples [19, 23].

Recovery under each set of extraction conditions was calculated relative to the maximum recovery obtained in the experimental design (denoted 100\%; extraction 15). Plots of the main effects for each extraction variable are shown in Fig. 1. The most important factor seems to be the volume of solvent used for extraction, because this results in the largest difference between the two amounts extracted by levels investigated in the experimental design (25 and $50 \mathrm{~mL}$ ). When $50 \mathrm{~mL}$ was used recovery of both verbenone and $c i s$-verbenol was almost $40 \%$ higher.

The mass of pine seed powder extracted was another important factor. For extraction of $5 \mathrm{~g}$ recovery was higher than for extraction of $10 \mathrm{~g}$ (30\% higher for verbenone and $32 \%$ higher for cisverbenol)

Other variables had little or no effect on recovery. Very similar mean recovery was recorded for both verbenone and cisverbenol and use of either DCM or EtOAc as extraction solvent. For the other variables, recovery of verbenone was $8 \%$ higher when the higher temperature $\left(50{ }^{\circ} \mathrm{C}\right)$ was used and $5 \%$ higher when MSAE was used instead of UAE. For cisverbenol results were similar, $7 \%$ higher recovery at the higher temperature $\left(50{ }^{\circ} \mathrm{C}\right)$ and $6 \%$ higher when MSAE was used. Because the main-effect plots furnished no definitive information about the best extraction conditions in respect of the method of extraction, the temperature of extraction, and the extracting solvent, plots of interactions between two variables were studied; these are shown in Fig. 2.

The interactions between extraction method (UAE or MSAE) and the most important extraction variables (extraction volume and mass of sample) were checked. It is apparent from Fig. 2 that increasing the extraction volume increased recovery similarly for both UAE and MSAE. This means there were no interactions between these two variables. It was, therefore, not possible to determine the best extractions
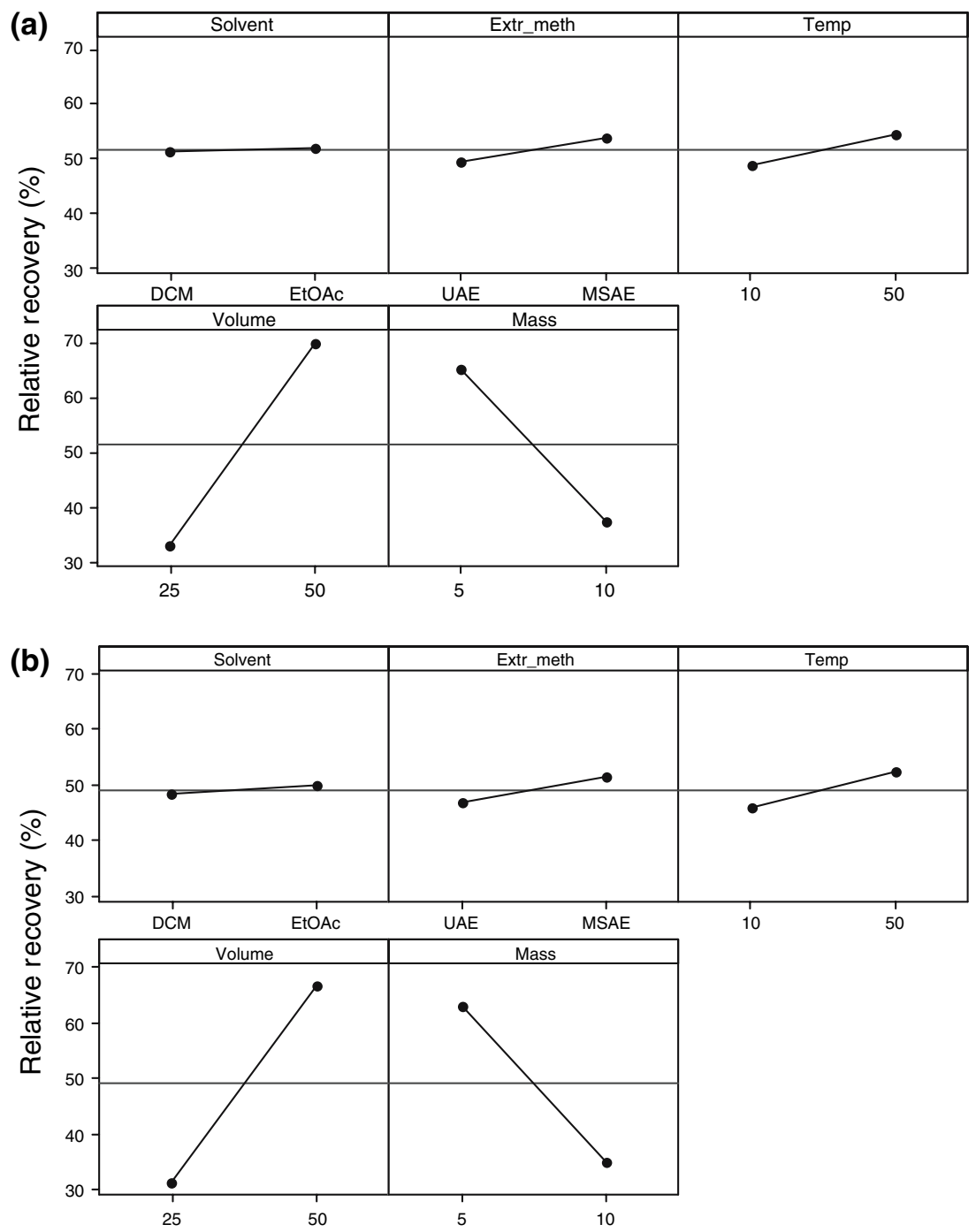

Fig. 1. Main-effects plot for verbenone (a) and cis-verbenol (b)

conditions for the extraction method on the basis of this interaction plot. When the interaction between the method of extraction and the amount of sample was evaluated it was found that reducing the mass of sample increased the recovery for both UAE and MSAE, as is also apparent from Fig. 2. For MSAE, average recovery was improved from $38-40$ to $75-78 \%$ for both $c i$-verbenol and verbenone when the mass of solid sample was reduced; for UAE recovery increased from $38-40$ to $58-60 \%$ only. Hence, MSAE resulted in higher average recovery than UAE when working with the optimum amount of sample.

There were no clear interaction effects between extraction temperature and extraction solvent, so no additional information could be extracted from the plots.

After evaluation of the main effects and the interaction effects, the values of the continuous variables (extraction temperature, volume of extracting solvent, and the mass of sample) were optimized. The starting values for this stage of the optimization were chosen on the basis of the results from the experimental design.

\section{Extraction Temperature}

Because no clear effect of extraction temperature on recovery was observed, a series of extractions was performed using $5 \mathrm{~g}$ sample, $50 \mathrm{~mL}$ EtOAc, and temperatures from 10 to $60{ }^{\circ} \mathrm{C}$. Recovery for each set of extraction conditions was calculated relative to the maximum recovery obtained in the temperature study $(100 \%)$.

It is clearly apparent from Table 2 that increasing the extraction temperature from 10 to $20{ }^{\circ} \mathrm{C}$ resulted in increased recovery; there was no difference for 
(a)

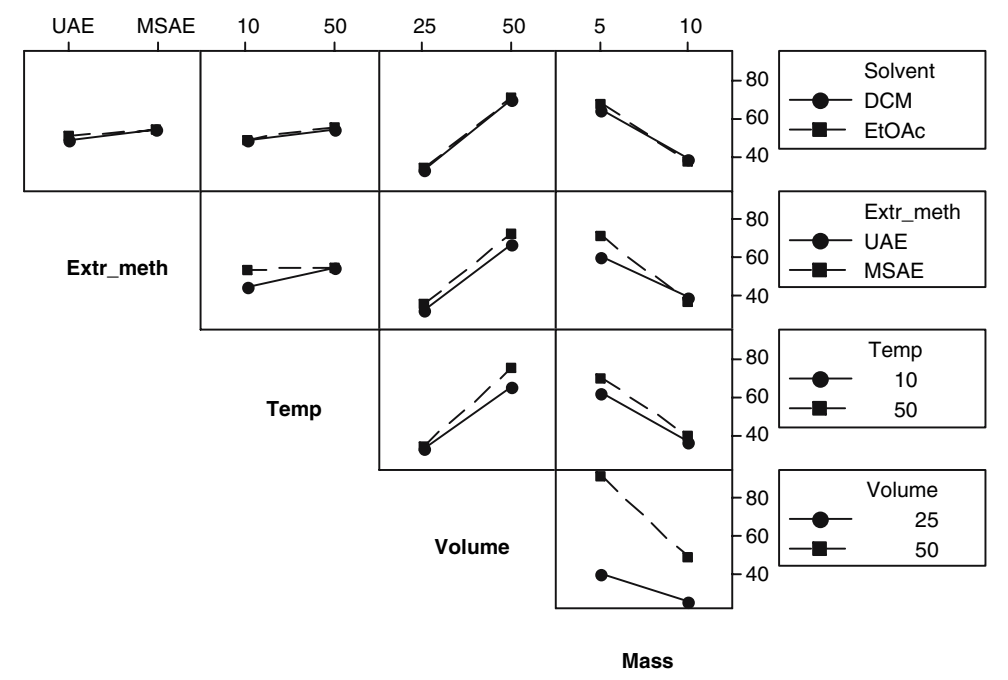

(b)

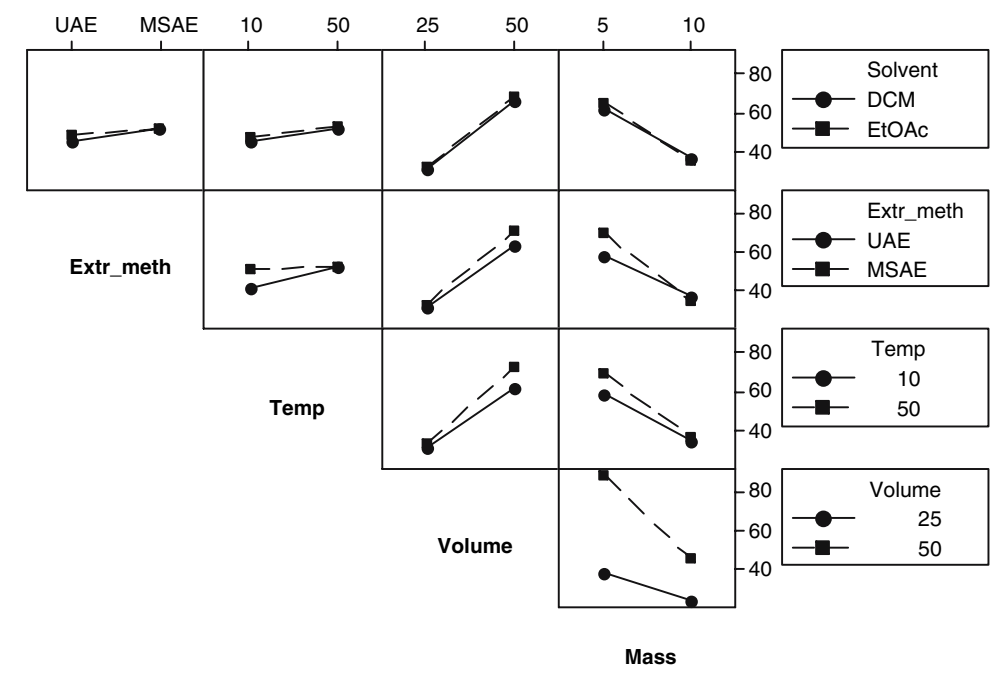

Fig. 2. Interaction plots for verbenone (a) and cis-verbenol (b)

Table 2. Recovery ${ }^{\mathrm{a}}$ obtained from extraction at different temperatures

\begin{tabular}{|lrr|}
\hline $\begin{array}{l}\text { Temp. } \\
\left({ }^{\circ} \mathrm{C}\right)\end{array}$ & \multicolumn{1}{l}{$\begin{array}{l}\text { cis-Verbenol } \\
(\%)\end{array}$} & \multicolumn{1}{l|}{$\begin{array}{l}\text { Verbenone } \\
(\%)\end{array}$} \\
\hline 10 & $86.2 \pm 3.5$ & $85.7 \pm 2.9$ \\
20 & $100.0 \pm 3.8$ & $100.0 \pm 1.8$ \\
30 & $95.6 \pm 3.8$ & $96.6 \pm 1.6$ \\
40 & $97.3 \pm 4.5$ & $96.6 \pm 2.5$ \\
50 & $86.8 \pm 5.6$ & $97.4 \pm 4.8$ \\
60 & $94.7 \pm 7.5$ & $96.2 \pm 6.5$ \\
\hline
\end{tabular}

a Relative to the amount obtained from the extraction with the highest recovery $\left(20^{\circ} \mathrm{C}\right)$

extractions performed at temperatures from 20 to $40{ }^{\circ} \mathrm{C}$ and higher temperatures resulted in a slight decrease in the average recovery for both verbenone and cis-verbenol. The higher the temperature the greater the errors in the measurement of recovery, most probably, because evaporation of the solvent during the extraction, resulted in changes in the contact
Table 3. Relative ${ }^{\mathrm{a}}$ recovery obtained by use

\begin{tabular}{|crr|}
\hline $\begin{array}{l}\text { Volume } \\
(\mathrm{mL})\end{array}$ & \multicolumn{1}{l}{$\begin{array}{l}\text { cis-Verbenol } \\
(\%)\end{array}$} & \multicolumn{1}{l|}{$\begin{array}{l}\text { Verbenone } \\
(\%)\end{array}$} \\
\hline 25 & $82.5 \pm 3.2$ & $80.2 \pm 1.9$ \\
50 & $89.9 \pm 3.4$ & $89.7 \pm 1.9$ \\
75 & $100.0 \pm 4.0$ & $100.0 \pm 2.3$ \\
100 & $93.8 \pm 2.9$ & $85.2 \pm 2.1$ \\
\hline
\end{tabular}

${ }^{\text {a }}$ Relative to the amount obtained from the extraction with the highest recovery $(75 \mathrm{~mL})$

surface between the sample and the solvent. Extraction at room temperature was therefore used in all experiments.

\section{Volume of Solvent}

Because $50 \mathrm{~mL}$ solvent resulted in higher recovery than $25 \mathrm{~mL}$, several experiments were performed using volumes larger than $50 \mathrm{~mL}$. Samples $(5 \mathrm{~g})$ were extracted of different volumes of solvent with 50,75 , or $100 \mathrm{~mL}$ ethyl acetate. The results are shown in Table 3. Recovery for different extraction conditions was calculated relative to the maximum recovery obtained in the solvent volume study $(100 \%)$. It is apparent the highest recovery was obtained by use of $75 \mathrm{~mL}$. This result must be related to the beaker in which the extractions were performed, because higher volumes result in a much lower contact area between the samples and the solvent.

\section{Sample Mass}

The amount of sample was the last condition studied during optimization. Because, in the experimental design, it was found that $5 \mathrm{~g}$ sample resulted in much greater recovery than $10 \mathrm{~g}$, a series of extractions was performed using between 2 and $5 \mathrm{~g}$ sample and $75 \mathrm{~mL}$ ethyl acetate at room temperature for $20 \mathrm{~min}$. The results obtained are given in Table 4. Recovery for each extraction condition was calculated relative to the maximum recovery obtained in the sample mass study (100\%).

It is apparent recovery of the compounds increased with the increasing mass up to $4 \mathrm{~g}$. For 4 and $5 \mathrm{~g}$ sample differences were small. It was therefore, concluded that any amount between 4 and $5 \mathrm{~g}$ could be used in the final method.

\section{Repeatability and Quantification}

Six extractions were performed under the optimized conditions. Table 5 shows the recovery obtained for both verbenone and cis-verbenol. RSDs were below $5 \%$ for both compounds. The amount of verbenone was almost twice that of cis-verbenol.

To check the method chosen resulted in quantitative extraction, a sample reextraction study was conducted on the six samples used in the repeatability study. The samples were extracted a second time using the same method. Neither verbenone nor cis-verbenol was detected in the second extracts.

The optimized method could therefore be used to determine both verbenone and $c i s$-verbenol in pine seeds. The method could be useful in taxonomic studies and in studies of the bioactivity of different varieties of pine. 
Table 4. Relative ${ }^{\mathrm{a}}$ recovery obtained by use of different masses of sample

\begin{tabular}{|lrr|}
\hline $\begin{array}{l}\text { Mass } \\
(\mathrm{g})\end{array}$ & \multicolumn{1}{l}{$\begin{array}{l}\text { cis-Verbenol } \\
(\%)\end{array}$} & \multicolumn{1}{l|}{$\begin{array}{l}\text { Verbenone } \\
(\%)\end{array}$} \\
\hline 2 & $53.0 \pm 2.4$ & $44.7 \pm 1.6$ \\
3 & $73.5 \pm 4.8$ & $64.8 \pm 1.7$ \\
4 & $90.4 \pm 4.9$ & $90.8 \pm 3.6$ \\
5 & $100.0 \pm 3.9$ & $100.0 \pm 3.2$ \\
\hline
\end{tabular}

a Relative to the amount obtained from the extraction with the highest recovery $(5 \mathrm{~g})$

\section{Acknowledgments}

The authors are most grateful to the Station Regionale des Semences de Chefchaouan (Chefchaouan, Morocco) for supplying the pine seeds. The Consejería de Presidencia (Junta de Andalucía) is also thanked for supporting the research under project $\mathrm{AM} / 08-2005$.

\section{References}

1. Dhar P, Ayala U, Andarge E, Morisseau S, Snyder-Leiby T (2004) J Essent Oil Res 16:612-616

2. Naigre R, Kalck P, Roques C, Roux I, Michl G (1996) Planta Med 62:275-277
Table 5. Repeatability of the method for cisverbenol and verbenone

\begin{tabular}{|lll|}
\hline No. & $\begin{array}{l}\text { cis-Verbenol } \\
\left(\mathrm{mg} \mathrm{kg}^{-1}\right)\end{array}$ & $\begin{array}{l}\text { Verbenone } \\
\left(\mathrm{mg} \mathrm{kg}^{-1}\right)\end{array}$ \\
\hline 1 & 0.397 & 0.790 \\
2 & 0.413 & 0.815 \\
3 & 0.411 & 0.808 \\
4 & 0.420 & 0.825 \\
5 & 0.435 & 0.838 \\
6 & 0.423 & 0.818 \\
$\operatorname{RSD}(\%)$ & 3.08 & 1.97 \\
\hline
\end{tabular}

3. Himejima M, Hobson KR, Otsuka T, Wood DL, Kubo I (1992) J Chem Ecol 18:1809-1818

4. Megalla SE, El-Keltawi NEM, Ross SA (1980) Herbal Pol 26:181-186

5. Santoyo S, Cavero S, Jaime L, Ibañez E, Señorans FJ, Reglero G (2005) J Food Protect 68:790-795

6. Shea PJ, McGregor MD, Daterman GE (1992) Aerial Can J For Res 22:436-441

7. Klepzig KD, Schlyter F (1999) J Econ Entomol 92:644-650

8. Fettkother R, Reddy GVP, Noldt U, Dettner K (2000) Chemoecology 10:1-10

9. Omolo MO, Okinyo D, Ndiege IO, Lwande W, Hassanali A (2004) Phytochemistry 65:2797-2802

10. Allison JD, Morewood WD, Borden JH, Hein KE, Wilson IM (2003) Environ Entomol 32:23-30

11. Angioni A, Barra A, Cereti E, Barile D, Coisson JD, Arlorio M, Dessi S, Coroneo
V, Cabras P (2004) J Agric Food Chem 52:3530-3535

12. Figueiredo AC, Miguel MG, Duarte AMF, Barroso JG, Pedro LG (2001) Flavour Fragr J 16:417-421

13. Jordan MJ, Martinez RM, Cases MA, Sotomayor J (2003) J Agric Food Chem 51:5420-5427

14. Gallori S, Flamini G, Bilia AR, Morelli I, Landini A, Vincieri F (2001) J Agric Food Chem 49:5907-5910

15. Marongiu B, Porcedda S, Caredda A, de Gioannis B, Vargiu L, la Colla P (2003) Flavour Fragr J 18:390-397

16. Umano K, Hagi Y, Nakahara K, Shoji A, Shibamoto T (2000) J Agric Food Chem 48:3463-3469

17. Kim NS, Lee DSJ (2002) J Chromatogr A 982:31-47

18. Paniwnyk L, Beaufoy E, Lorimer JP, Mason TJ (2001) Ultrason Sonochem 8:299-301

19. Palma M, Barroso CG (2002) Anal Chim Acta 458:119-130

20. Wu J, Lin L, Chau F (2001) Ultrason Sonochem 8:347-352

21. Carlow SJ, Ayers L, Bailey A, John B, Richardson A, Shepherd B, Woosley RS, Butcher DJ (2006) Microchem J 83:91-97

22. Péres VF, Saffi J, Melecchi MIS, Abad FC, Jacques RA, Martinez MM, Oliveira EC, Caramão EB (2006) J Chromatogr A 1105:115-118

23. Palma M, Taylor LT (2001) J Agric Food Chem 49:628-632 